Article

\title{
Performance of Concrete with Waste Granite Powder: The Effect of Superplasticizers
}

\author{
Elyas Asadi Shamsabadi ${ }^{1}$, Mansour Ghalehnovi ${ }^{1}{ }^{1}$, Jorge de Brito ${ }^{2, *}$ and Ali Khodabakhshian ${ }^{1}$ \\ 1 Department of Civil Engineering, Ferdowsi University of Mashhad, Mashhad 9177948974, Iran; \\ E.asadi@mail.um.ac.ir (E.A.S.); Ghalehnovi@ferdowsi.um.ac.ir (M.G.); \\ khodabakhshian.ali@mail.um.ac.ir (A.K.) \\ 2 CERIS-ICIST, Department of Civil Engineering, Architecture and Georresources, Instituto Superior Técnico, \\ Universidade de Lisboa, Av. Rovisco Pais, 1049-001 Lisbon, Portugal \\ * Correspondence: jb@civil.ist.utl.pt
}

Received: 4 September 2018; Accepted: 24 September 2018; Published: 2 October 2018

check for updates

\begin{abstract}
Granite stone is highly demanded by construction sector. In the processing stage, great amounts of waste powder are produced that can be used as cement replacement in concrete production. Reduced workability is the first problem of this replacement and it can be mitigated by using superplasticizers (SP). This study was carried out to limit the disadvantages related to waste granite powder (WGP) use through the use of SP. For this purpose, 19 concrete mixes containing various types of SP with different contents and WGP as cement replacement were appraised. Fresh concrete density, splitting tensile strength, electrical resistivity, compressive strength and resistance to sulphate attack tests were conducted. The mixes were assessed based on their environmental impact, economic, and mechanical performance. The results have shown that SP can eliminate most disadvantages caused by using stone waste, particularly negative effects on the mechanical properties. They can even improve some properties of concrete, including electrical resistivity by up to around 90\%. Furthermore, the concrete mixes PT5, PF5, and PF10, which were made with both SP and stone waste, obtained the best results, with over 30\% improvement in the multi-criteria evaluation index values compared to the mix W0 (reference mix). The proper use of WGP as replacement for cement would have environmental benefits and help the economy of the granite stone industry.
\end{abstract}

Keywords: waste granite powder; superplasticizer; cement replacement; multi-criteria index; concrete

\section{Introduction}

With its flexibility and low cost of materials, production and maintenance, concrete has become the most selected material in the construction industry. The concrete industry is one of the biggest contributors to greenhouse gas emissions and the largest consumer of natural resources worldwide, because over 10 billion tonnes of concrete are made every year [1]. The world population growth and technological evolution are resulting in greater production of concrete, to construct residential houses and commercial buildings, a reduction of natural resources such as aggregates and water, and an increase of greenhouse gas emissions as a result of cement production; consequently, concerns about the world environment will increase in the future.

As well as concrete, cladding stones are one of the highly demanded materials in the construction industry. According to Figure 1, Iran is one the major producers of stone, especially granite, and consequently of its by-products. Granite stone is one of the highly used building materials and leads to a high amount of waste, amounting to almost $50 \%$ of the volume of the final granite 
products, throughout its processing and extraction [2,3]. Granite waste has accumulated over the years and only negligible amounts have been used, while the rest is dumped resulting in environmental problems. At the moment, nearly $25 \%$ of the total area of the industry premises is occupied by the by-products that are dumped in open yards [4]. Open sky mining, as in the case of granite and other type of building stone quarries, leads to environmental problems, such as obstruction of drains in the rainy season, dust-related nuisance, and air pollution (from fine particles of slurry, sized less than 363 microns, becoming air borne). Slurry affects the productivity of the land as a result of decreasing porosity, and water absorption and also percolation. Additionally, due to long-term deposition, slurry dumping areas are not able to support vegetation and remain degraded, while the finer particles seriously influence underground water availability and stop the flow regime of aquifers [5].

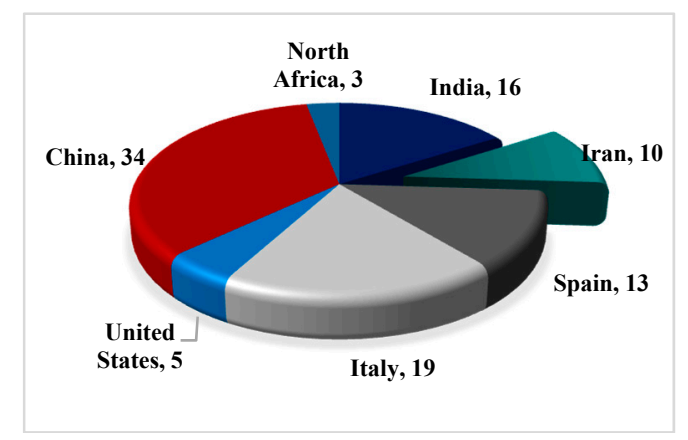

Figure 1. Stone production of different countries/regions (\%) [5].

In addition, cement is the most environment-pollutant component of concrete. The cement industry releases more than 500 thousand tonnes of sulphur dioxide, nitrogen oxide and carbon monoxide into the atmosphere [6] and is also responsible for $7 \%$ of the released carbon dioxide $\left(\mathrm{CO}_{2}\right)$ in the world [3]. Waste granite powder (WGP) is a suitable choice for cement replacement due to its high silica content. A reduction in waste generation helps preserve the environment and the economy of the granite stone industry by promoting value-added products from granite stone waste [4].

A study by Ramos et al. [3] obtained the influence of "granitic-quarry sludge waste" incorporation on the durability and mechanical performances of mortars. They state that the chemical content of granite waste complies with the chemical requirements in ASTM 618 [7] regarding pozzolanic materials. In general, most of granite waste has the same chemical composition and can, therefore, be used as pozzolanic matter to produce concrete. They reported that, if the particles' size is even finer than that of cement particles, an improvement of almost $70 \%$ can be seen in the resistance to chlorides. Also more resistance against alkali-silica reactions will result from finer particles when granite powder is used as $10 \%$ replacement of cement.

Bacarji et al. [8] showed the feasibility of granite and marble waste as a green substitute to cement. In this study, both waste by-products were shown to be non-reactive materials and may act as a filler according to the chemical analysis and particle size distribution. With increasing replacement ratios of cement with marble and granite waste, the slump tends to slightly decrease. Elmoaty [9] used granite powder at $5 \%, 8 \%, 10 \%$ and $15 \%$ as cement replacement and filler in concrete. In this research, the effect of the granite powder on the mechanical characteristics, corrosion resistance and hydration products was investigated: an improvement in concrete corrosion cracking time and mechanical characteristics for 5.0\% replacement was seen, and no significant changes were reported in microstructure, degree of hydration and hydration products from using granite powder. Marmol et al. [10] reported that high-strength coloured mortar can be prepared from stone waste. According to this research, reddish pigments can be obtained by calcination of granite waste at $700-900{ }^{\circ} \mathrm{C}$ for a short time, which can be used in the production of coloured concrete, due to $\mathrm{Fe}_{2} \mathrm{O}_{3}$ crystallizing during the after heating treatment, with acceptable compressive strength $\left(f_{\mathrm{cm}}\right)$. A number of researches have shown that the incorporation of several types of stone waste in concrete production 
results in lower slump of fresh concrete in comparison with traditional concrete, and increasing the waste content further lowers the slump. It is argued that the particle size of the stone aggregates is the reason behind this lower slump [5].

More recently, researchers have produced concrete with granite waste as cement replacement with a focus on pozzolanic activity, durability and higher substitution ratios. Medina et al. [11], in 2017, evaluated the performance of a new blended cement incorporating $10 \%$ or $20 \%$ granite sludge as clinker replacement, analyzing the chemical, rheological, mechanical and microstructural properties of the end product. They found that granite sludge as partial cement replacement can shorten the initial time setting depending on the substitution ratio, with higher ratios resulting in less effect on the setting time. More interestingly, the new developed blended cement showed slight changes in hydration products and morphology. Mashaly et al. [12], in 2018, studied the properties of mortar and concrete incorporating granite sludge as cement replacement with various substitution ratios from 0 to $40 \%$. The results of this study clearly highlight the potential effects of granite sludge on an enhanced durability of concrete including abrasion, freeze and thaw cycles and sulfate attack resistance. In addition, they concluded that granite sludge may be effectively used in concrete bricks, paving units, and cement tiles' production. An enhanced durability of concrete incorporating granite sludge was also demonstrated in the study conducted by Medina et al. [13], in 2018, with aesthetically sensitive applications. Vazzoler et al. [14], in 2018, investigated the microstructural characteristics of paste produced with ornamental stone processing waste after heat treatment showing low pozzolanic activity, resulting in a denser final product due to the filler effect and a probable small pozzolanic reaction.

Nowadays, admixtures and additions are indispensable components of concrete. In recent years, some researchers studied the simultaneous effects of superplasticizers (SP) and different waste materials on concrete [15-18]. Most of them reported that using SP, by decreasing the water to cement ratio $(\mathrm{w} / \mathrm{c})$ and better dispersing the cement particles, can overcome the disadvantages due to the use of waste. Pereira et al. [16], for instance, reported a higher compressive strength of concrete incorporating recycled aggregates and superplasticizers than that of the same concrete mix with no admixtures, while Bravo et al. [19] concluded that superplasticizers are more effective on the shrinkage and durability properties of concrete produced with construction and demolition waste aggregates than that with concrete recycled aggregates. According to them, in some cases of chloride ingress, superplasticizers could not effectively improve the performance of concrete made with construction and demolition waste aggregates. However, the lack of research on the capability of superplasticizers in improving the general performance of concrete produced with by-products as cement partial replacements highlights the need for further studies.

The main objectives of this paper are using a polycarboxylate-based superplasticizer (PPS) (due to its steric hindrance mechanism) to eliminate the disadvantages caused by WGP in concrete and appraising the environmental impact, economic performance and mechanical characteristics of concrete made with both WGP and PPS, which has not been evaluated before. The paper comprises two main parts: experimental works and multidimensional performance evaluation.

\section{Materials}

\subsection{Cement}

The cement is commercial Type 2 Portland with specific gravity 3.2 and sourced from Mashhad Cement Company. Its particle size distribution of the cement (Figure 2) is performed by laser technique. 


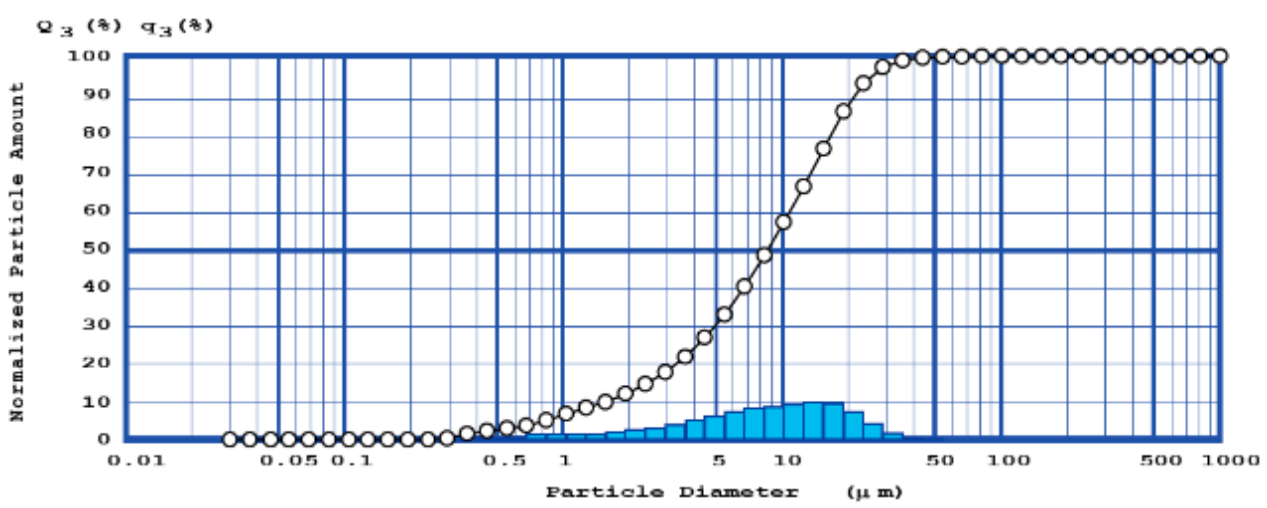

Figure 2. Particle size distribution of cement.

\subsection{Granite Waste}

Waste granite powder (WGP), a by-product of the granite processing industry, was used in this research. Its specific gravity is (2.5) lower than that of the cement (3.2). In addition, Figure 3 shows its grain size distribution. The average diameter of cement is lower than that of granite powder and this can be considered as one of the reasons to decrease the mechanical characteristics of concrete.

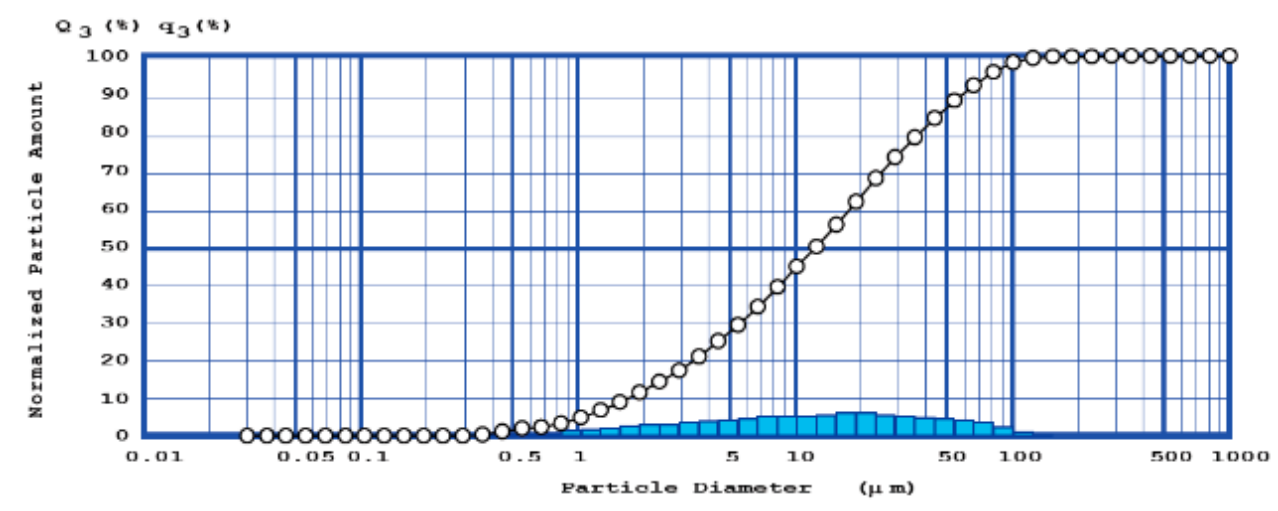

Figure 3. Grain size distribution of waste granite powder obtained by laser diffraction.

The chemical analysis, using X-ray Fluorescence technique, showed that WGP contains about $72.9 \%$ of soluble silica $\left(\mathrm{SiO}_{2}\right), 14.65 \%$ of alumina $\left(\mathrm{Al}_{2} \mathrm{O}_{3}\right)$ and $1.70 \%$ of ferric oxide $\left(\mathrm{Fe}_{2} \mathrm{O}_{3}\right)$. Based on ASTM C618 [7], since their sum is over 70\%, WGP can be introduced to concrete as pozzolanic material. The chemical characteristics of granite waste and cement is shown in Table 1.

Table 1. Chemical characteristics of cement and waste granite powder (WGP).

\begin{tabular}{ccc}
\hline Composition & Cement (\%) & Granite Powder (\%) \\
\hline $\mathrm{SiO}_{2}$ & 21.63 & 72.9 \\
$\mathrm{Al}_{2} \mathrm{O}_{3}$ & 4.27 & 14.65 \\
$\mathrm{Fe}_{2} \mathrm{O}_{3}$ & 3.45 & 1.7 \\
$\mathrm{CaO}$ & 63.25 & 1.5 \\
$\mathrm{Na} 2$ & - & 3.85 \\
$\mathrm{~K}_{2} \mathrm{O}$ & - & 3.98 \\
$\mathrm{MgO}$ & 2.77 & 0.37 \\
$\mathrm{TiO}$ & - & 0.235 \\
$\mathrm{MnO}$ & - & 0.026 \\
$\mathrm{SO} 3$ & 2.02 & 0 \\
$\mathrm{C} 3 \mathrm{~A}$ & 5.48 & - \\
$\mathrm{P}_{2} \mathrm{O}$ & - & 0.088 \\
$\mathrm{~L} . \mathrm{O} . \mathrm{I}$ & 1.5 & 0.41 \\
\hline
\end{tabular}




\subsection{Aggregates}

The maximum coarse aggregate size was $19 \mathrm{~mm}$, and the fine aggregate was natural sand, with specific gravity of 2.67 and 2.65 respectively. Sieve analysis was performed for the aggregates based on ASTM C136 [20] specification (Figure 4).

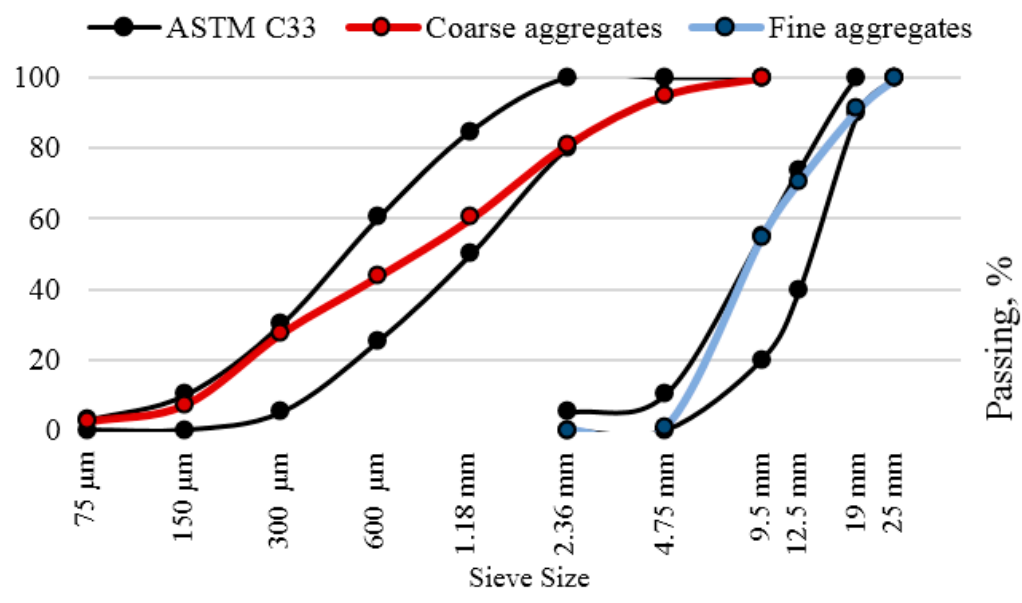

Figure 4. Particle size distribution of aggregates.

\subsection{Superplasticizers and Water}

Two commercial SP were used: a standard one henceforth called SPP, whose chemical basis is an aqueous solution of modified polycarboxylic polymers; a high-performance SP henceforth called SPL, whose chemical basis is an aqueous solution of lignosulphonate polymers. In addition, tap water was used to produce the concrete mixes based on ASTM C1602 [21].

\section{Experimental Program}

The volumetric method (ACI 211.1, [22]) was used to design the mix composition. At first, three mixes were prepared to understand the performance of two SP (steric hindrance and electrostatic mechanisms): one without any type of SP, another containing SPP at $0.7 \%$ by cement weight and a third one containing both SPP and SPL at $0.35 \%$ each by cement weight. After a trial and error process, it was found that the SPP was more efficient in decreasing the $\mathrm{w} / \mathrm{c}$ for constant slump. Based on the initial results, to continue the experimental program, three series of concrete mixes were designed. The first two series were based on the first and second concrete mixes cited above and the third one contained SPP at $1 \%$ by cement weight. Each series had six mixes with increasing WGP incorporation ratios: $0 \%, 5 \%, 10 \%, 20 \%, 30 \%$ and $40 \%$ by cement weight. In order to keep slump in the range of $70-90 \mathrm{~mm}$, the water/binder ratio was fine-tuned in each mix. The composition of the various mixes is listed in Table 2.

For all mixes, the aggregates were weighed in dry condition and mixing proceeded for 7-8 $\mathrm{min}$ in a 150-L mixer. 
Table 2. Concrete mix composition and slump.

\begin{tabular}{|c|c|c|c|c|c|c|c|c|c|c|}
\hline $\mathbf{N}$ & Mix & Cement $\left(\mathrm{kg} / \mathrm{m}^{3}\right)$ & W/C Ratio & WGP $\left(\mathrm{kg} / \mathrm{m}^{3}\right)$ & Water $\left(\mathrm{kg} / \mathrm{m}^{3}\right)$ & Coarse Aggregate $\left(\mathrm{kg} / \mathrm{m}^{3}\right)$ & Fine Agregate $\left(\mathrm{kg} / \mathrm{m}^{3}\right)$ & $\operatorname{SPP}\left(\mathrm{kg} / \mathrm{m}^{3}\right)$ & SPL $\left(\mathrm{kg} / \mathrm{m}^{3}\right)$ & Slump $\left(\mathrm{kg} / \mathrm{m}^{3}\right)$ \\
\hline 1 & W0 & 400 & 0.5 & 0 & 200 & 1000 & 714 & 0 & 0 & 80 \\
\hline 2 & W5 & 380 & 0.5 & 20 & 200 & 1000 & 709 & 0 & 0 & 75 \\
\hline 3 & W10 & 360 & 0.51 & 40 & 204 & 995 & 699 & 0 & 0 & 80 \\
\hline 4 & W20 & 320 & 0.52 & 80 & 208 & 989 & 685 & 0 & 0 & 75 \\
\hline 5 & W30 & 280 & 0.525 & 120 & 210 & 987 & 673 & 0 & 0 & 75 \\
\hline 6 & W40 & 240 & 0.54 & 160 & 216 & 979 & 656 & 0 & 0 & 90 \\
\hline 7 & PT0 & 400 & 0.37 & 0 & 146.2 & 1069 & 783 & 3 & 0 & 75 \\
\hline 8 & PT5 & 380 & 0.375 & 20 & 148.2 & 1067 & 775 & 3 & 0 & 80 \\
\hline 9 & PT10 & 360 & 0.375 & 40 & 148.2 & 1067 & 771 & 3 & 0 & 75 \\
\hline 10 & PT20 & 320 & 0.38 & 80 & 150.2 & 1064 & 759 & 3 & 0 & 85 \\
\hline 11 & РT30 & 280 & 0.385 & 120 & 152.2 & 1061 & 747 & 3 & 0 & 75 \\
\hline 12 & PT40 & 240 & 0.39 & 160 & 154.2 & 1059 & 735 & 3 & 0 & 80 \\
\hline 13 & PF0 & 400 & 0.34 & 0 & 133.6 & 1085 & 798 & 4 & 0 & 85 \\
\hline 14 & PF5 & 380 & 0.34 & 20 & 133.6 & 1085 & 794 & 4 & 0 & 80 \\
\hline 15 & PF10 & 360 & 0.34 & 40 & 133.6 & 1085 & 789 & 4 & 0 & 85 \\
\hline 16 & PF20 & 320 & 0.345 & 80 & 135.6 & 1083 & 777 & 4 & 0 & 85 \\
\hline 17 & PF30 & 280 & 0.35 & 120 & 137.6 & 1080 & 765 & 4 & 0 & 90 \\
\hline 18 & PF40 & 240 & 0.35 & 160 & 137.6 & 1080 & 756 & 4 & 0 & 90 \\
\hline 19 & PL0 & 400 & 0.43 & 0 & 170.5 & 1037 & 751 & 1.5 & 1.5 & 80 \\
\hline
\end{tabular}




\subsection{Slump Test}

Slump tests were considered to assess the workability of the mixes. The procedures followed ASTM Standard C143 [23].

\subsection{Density of Fresh Concrete}

The fresh-density of the mixes are performed based on ASTM Standard C138 [24].

\subsection{Compressive Strength and Splitting Tensile Strength Tests}

The $f c m$ is performed at 180, 90, 28 and 7 days (at each testing age, three concrete samples with $100 \mathrm{~mm}$ cubic are considered). For the splitting tensile strength $\left(f_{\mathrm{ctm}}\right)$ test, three cylindrical samples (D $100 \mathrm{~mm} \times \mathrm{L} 200 \mathrm{~mm}$ ) used at each testing age. The mentioned tests are performed base on BS EN 12390-3 [25] and ASTM C496 [26], respectively.

\subsection{Sulphate Attack Resistance Test}

After 28 days water curing, three concrete cubes per mix were immersed in a $5 \% \mathrm{Na}_{2} \mathrm{SO}_{4}$ solution $(v / v)$ for 180 days. The resistance to sulphate attack (SA) coefficient of the concrete was found according to the following formula:

$$
k_{f}=\frac{f_{n}}{f_{k}} \times 100
$$

where $k_{f}$ is the resistance to SA coefficient of concrete (\%); $f_{n}$ the average value of $f_{\mathrm{cm}}$ obtained from three $100 \mathrm{~mm}$ cubic specimens after 180 days SA (MPa); and $f_{0}$ the average value of $f_{\mathrm{cm}}$ of three $100 \mathrm{~mm}$ cubic specimens at the same curing age as the concrete being subjected to SA (MPa).

\subsection{Electrical Resistivity (ER)}

As shown in Equations (2) and (3), the ER of an electrolyte is inversely and linearly proportional to the cross-sectional area and the length of the sample, respectively [27].

$$
\begin{gathered}
\rho=R \frac{A}{L} \\
R=\frac{V}{I}
\end{gathered}
$$

where $R$ is the resistance in $\Omega ; \rho$ the resistivity in $\mathrm{k} \Omega \cdot \mathrm{cm} ; V$ the voltage in $\mathrm{v}$; I current in $\mathrm{mA} ; L$ the length of the sample in $\mathrm{cm}$; and $A$ the cross-sectional area of the sample in $\mathrm{cm}^{2}$.

To obtain the ER of each concrete, direct current was obtained in the circuit shown in Figure 5. Three cylindrical specimens were tested for each mix after 56 and 90 days. One steel plate was stuck to each side of the specimen using low slump cement paste. After that, the samples were set in the circuit. Current and voltage values for each specimen were recorded at seven voltages ranging from 2 $\mathrm{v}$ to $14 \mathrm{v}$ at $2 \mathrm{v}$ intervals. Then the ER of each specimen was calculated at regular intervals according to Equation (1). Then, the average of all seven ER values was calculated for each sample. Eventually, the average ER of three specimens was calculated and reported for each mix. 


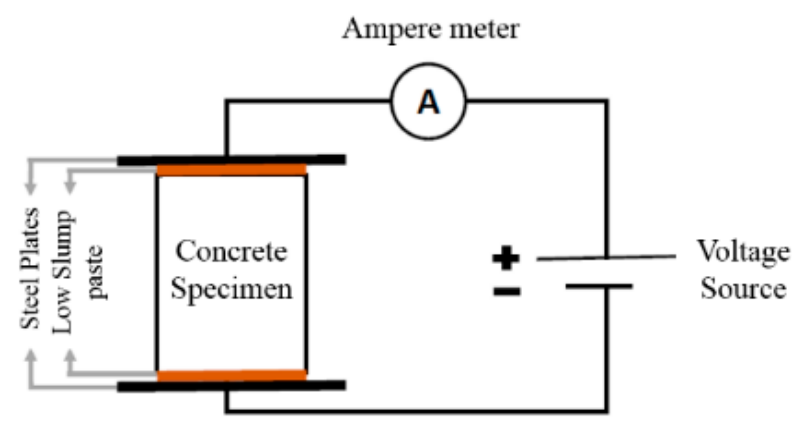

Figure 5. Schematic view of the circuit of the ER test.

\subsection{Consolidated Evaluation}

\subsubsection{Environmental Assessment}

The main factors of concrete production from an environmental point of view are prioritized as follows [28]:

- High priority: $\mathrm{CO}_{2}$, resource (water), water quality;

- Medium priority: secondary raw materials, recycling/waste minimization;

- Low priority: resource (energy).

In this study, according to the mentioned research, the carbon footprint and water used were considered as environmental evaluation factors of concrete production.

Lippiatt [29] derived a single index, uttered in grams of $\mathrm{CO}_{2}$ per functional unit of product, to estimate the content of $\mathrm{CO}_{2}$ that equivalent to global warming potential (GWP):

$$
\text { Global warming index }=\sum_{i} w_{i} \times G W P_{i}
$$

where $W_{i}$ is the weight (in grams) of inventory flow $i$; and $G W P_{i}$ grams of $\mathrm{CO}_{2}$ with the same heat entrapping potential as one gram of inventory flow I (Table 3).

Table 3. BEES GWP correspondence factors ([29]).

\begin{tabular}{cc}
\hline Flow (i) & $\mathbf{G W P}_{\mathbf{i}}\left(\mathbf{C O}_{\mathbf{2}}\right.$-Equivalents) \\
\hline $\mathrm{CO}_{2}$ & 1 \\
Methane & 24 \\
Nitrous oxide & 360 \\
\hline
\end{tabular}

The GWP data of the raw materials (water, SP, aggregates and cement) used to produce $1 \mathrm{~m}^{3}$ were sourced from the following studies [30-39]. According to the collected data, formulas 5 and 6 were derived (they determine the water used and carbon footprint until the concrete production stage without transportation). In a few cases the extreme case scenario and for some components the average of various studies have been used. Even though Flower and Sanjayan [40] reported that the influence of the admixture on the environmental assessment can be ignored, in this study that effect was determined.

$$
\begin{gathered}
G W P_{i}=1 \times C_{i}+2.16 \times S P_{i}+0.0004 \times W_{i}+0.003 \times A_{i} \\
W U_{i}=0.7 \times C_{i}+1 \times W_{i}+6.04 \times S P_{i}
\end{gathered}
$$

where $G W P_{i}$ is the global warming potential score of concrete mix $i ; W U_{i}$ the water used score to produce concrete mix $i ; C_{i}$ the cement content of concrete mix $i\left(\mathrm{~kg} / \mathrm{m}^{3}\right) ; W_{i}$ the water content of concrete mix $i\left(\mathrm{~kg} / \mathrm{m}^{3}\right) ; A_{i}$ the aggregate content of concrete mix $i\left(\mathrm{~kg} / \mathrm{m}^{3}\right)$; and $S P_{i}$ the SP content of concrete $\operatorname{mix} i\left(\mathrm{~kg} / \mathrm{m}^{3}\right)$. 
Both index values were determined for each mix. Since both factors are very important, their weight factors were assumed equal. Then, After standardizing the calculated index values, the environmental index (EI) for each concrete was found according to following formula [29]:

$$
\text { EnvScore }_{i}=\sum_{k=1}^{p} \text { IAScore }_{i k}
$$

where $\operatorname{EnvScore}_{i}$ is the environmental performance score for concrete mix alternative $i ; p$ the number of environmental impact categories; and IAScore $i k$ the weighted and normalized impact assessment score for alternative $i$ with respect to environmental impact $k$ :

$$
\operatorname{IAScore}_{i k}=\frac{I A_{i k} \times I V_{w t_{k}}}{\operatorname{Max}\left\{I A_{1 k}, I A_{2 k}, \ldots, I A_{m k}\right\}} \times 100
$$

Equation (8) was changed to consider the correction factor obtained from Section 3.6.3 as follows:

$$
\operatorname{IAScore}_{i k}=\frac{I A_{i k} \times I V_{w t_{k}} \times T_{i}}{\operatorname{Max}\left\{I A_{1 k}, I A_{2 k}, \ldots, I A_{m k}\right\}} \times 100
$$

where $I A_{i k}$ is the raw impact assessment score for alternative $i$ with respect to impact $k$; $I V w t_{k}$ the impact category importance weight for impact $k ; m$ the number of product alternatives; $I A_{m k}$ the raw impact assessment score for alternative $\mathrm{m}$ with respect to impact $k$; and $T_{i}$ the environmental and economic correction coefficient of concrete mix $i$.

\subsubsection{Economic Assessment of Concrete Mixes}

The cost of concrete mixes was found by considering the results of sellers' reports for each of its component, resulting in the following normalized formula:

$$
\text { Cost }_{i}=1 \times C_{i}+45 \times S P_{i}+0.0034 \times W_{i}+0.1 \times A_{i}
$$

where $\operatorname{Cost}_{i}$ is the normalized cost to produce $1 \mathrm{~m}^{3}$ of concrete mix $i ; C_{i}$ the cement content of concrete mix $i\left(\mathrm{~kg} / \mathrm{m}^{3}\right) ; W_{i}$ the water content of concrete mix $i\left(\mathrm{~kg} / \mathrm{m}^{3}\right) ; A_{i}$ the aggregate content of concrete $\operatorname{mix} i\left(\mathrm{~kg} / \mathrm{m}^{3}\right)$; and $S P_{i}$ the $S P$ content of concrete mix $i\left(\mathrm{~kg} / \mathrm{m}^{3}\right)$.

\subsubsection{Correction Coefficient}

Different mechanical properties result in different volume of concrete needed to build a structure. Using greater amount of concrete causes more environmental effects, and increases costs. This fact need to be considered through a correction coefficient to obtain comparable results. Figure 6 shows a simplified overview of columns supporting an isostatic beam. The beam span is $5 \mathrm{~m}$, and the columns are $3.5 \mathrm{~m}$ high. The applied loads on the beam consist of a permanent live load of $6 \mathrm{kN} / \mathrm{m}$ and its own weight of $4.8 \mathrm{kN} / \mathrm{m}$ as a dead load. All other concrete and steel reinforcement designs were calculated based on ACI 318 [41]. According to the results, if the $f_{\mathrm{cm}}$ increases, less material is required to bear the existing load. So, a reduction coefficient can be defined by which the ranges of environmental and economic indexes reduction in the assessment stage can be determined [42]. The correction coefficients regarding $f_{\mathrm{cm}}$ are presented in Table 4 .

Table 4. Results of the frame sections design.

\begin{tabular}{ccccccccc}
\hline$f c m(\mathbf{M P a})$ & $\mathbf{2 2}$ & $\mathbf{3 3}$ & $\mathbf{3 9}$ & $\mathbf{4 4}$ & $\mathbf{4 9 , 5 0}$ & $\mathbf{5 4 , 5 5}$ & $\mathbf{5 7 , 5 9}$ & $\mathbf{6 2 , 6 4 , 6 6}$ \\
\hline Concrete volume $\left(\mathrm{m}^{3}\right)$ & 0.6 & 0.53 & 0.51 & 0.5 & 0.47 & 0.46 & 0.45 & 0.43 \\
Correction coefficient & 1 & 0.8867 & 0.8473 & 0.8229 & 0.7844 & 0.7669 & 0.7495 & 0.7138 \\
\hline
\end{tabular}




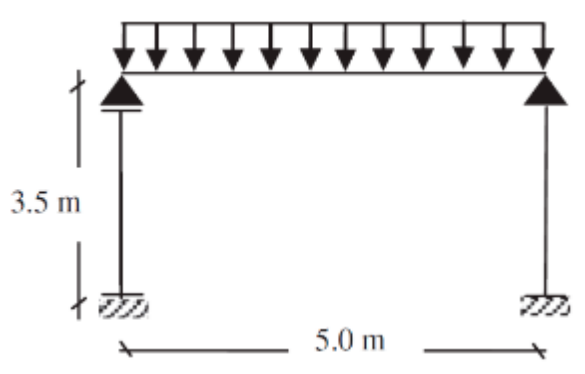

Figure 6. Simplified overview of a columns-supported isostatic beam.

\subsubsection{Consolidated Index}

Based on study by Lippiatt [43], in developing countries, the weight of the costs and EI can be similar. However, to assess the characteristics of the mixes, the $f_{\mathrm{cm}}$ is one of most important criteria. Accordingly, the weigh coefficient of all three indexes was considered equal. However, different weight coefficients can be used for various locations and times. Eventually, for simultaneous economic, mechanical and environmental evaluation of each concrete mix, the following formula were used:

$$
\begin{aligned}
& E C M_{i}=\frac{\operatorname{Mec}_{\text {in }}}{\text { EnvScore }_{\text {in }}+\text { Cost }_{\text {in }}} \\
& \text { EnvScore }_{\text {in }}=\frac{\text { EnvScore }_{i}}{M A X\left\{\text { EnvScore }_{1}, \text { EnvScore }_{2}, \ldots, \text { EnvScore }_{m}\right\}} \\
& \operatorname{Cost}_{i n}=\frac{\operatorname{Cost}_{i} \times T_{i}}{M A X\left\{\operatorname{Cost}_{1} \times T_{1}, \operatorname{Cost}_{2} \times T_{2}, \ldots, \operatorname{Cost}_{m} \times T_{m}\right\}} \\
& M e c_{i n}=\frac{M e c_{i}}{M A X\left\{M e c_{1}, M e c_{2}, \ldots, M e c_{m}\right\}}
\end{aligned}
$$

where $E C M_{j}$ is the consolidated index of economic, environmental and mechanical performance of concrete mix $i$; EnvScore ${ }_{i n}$ the normalized environmental score of concrete mix $i$; Cost ${ }_{i n}$ the normalized economic score of concrete mix $i ; M_{e c}$ in the normalized 28-day $f_{\mathrm{cm}}$ score of concrete mix $i ; m$ the number of concrete mix alternatives; and $T_{i}$ the environmental and economic correction coefficient of concrete mix $i$.

\section{Results and Discussion}

\subsection{Effect of Superplasticizer and WGP on Slump}

As seen in Figure 7, the water/binder increases for the same target slump by increasing the incorporation of WGP. However, the negative effect of WGP on the workability decreases with SP's content. In series W, the water/binder ratio of the mix with $40 \%$ WGP increased around $10 \%$ relative to the mix without WGP, while in the other two series the increase was $5.4 \%$ and $2.9 \%$. This shows that the SP can eliminate the negative effect of granite powder on the slump and greater SP content leads to much lower negative effect.

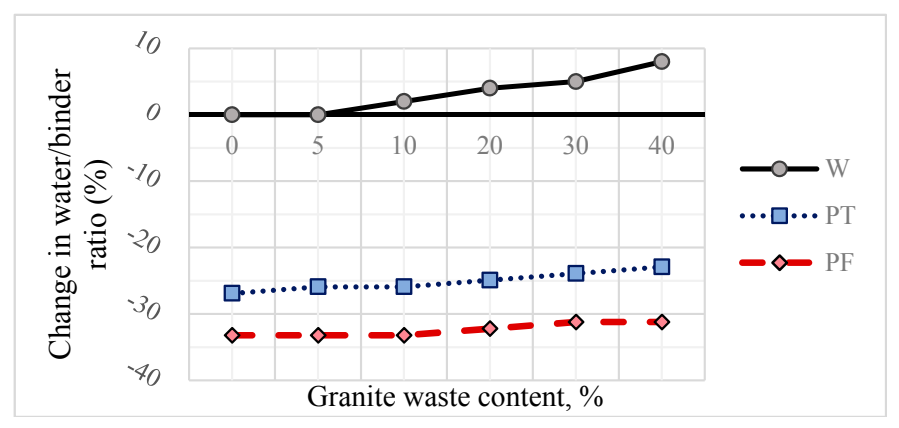

Figure 7. W/c versus percentage of cement replacement by WGP. 


\subsection{Density of Fresh Concrete}

Figure 8 shows that the fresh-density of the mix is maximum when 5\% of WGP introduced, as a result of better cement particle dispersion of the granite powder. At more than $5 \%$, the density of concrete decreases due to lower specific gravity of WGP than cement. The downward trend in high substitution ratios continues, which contradicts the results of [44]. They reported an increase in density and strength at $30 \%$ substitution ratio. The difference in the results may be related to different particle distribution and processing method of the granite stone.

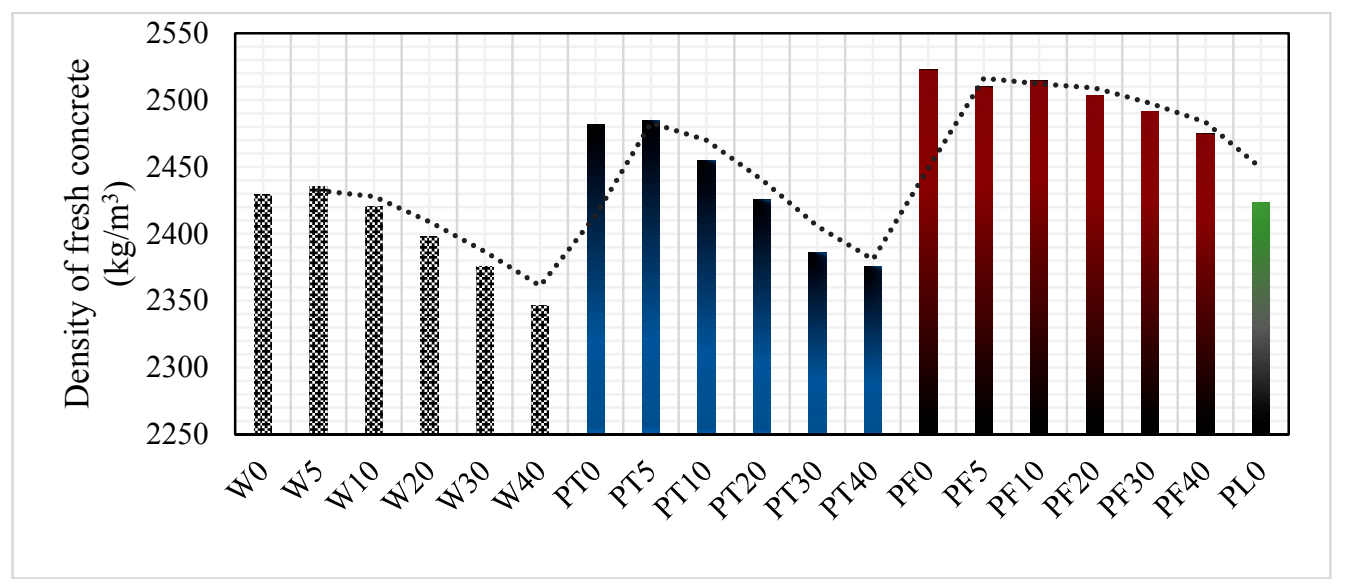

Figure 8. Fresh-density of the mixes.

\subsection{Compressive Strength}

The results show that replacing $5 \%$ cement did not significantly change the $f_{\mathrm{cm}}$ and in some cases it even slightly increased it (Figure 9). This can be due to the improvement in mix density resulting from better dispersion of the cement particles around the granite particles, as noted by Elmoaty [9]. According to this author, cement replacement with granite in small amounts leads to better dispersion of cement particles in the mix which results in better cement reactions and finally improvements in strength and other characteristics of concrete. The results in Figure 10, related with the fresh-density of concrete and $f_{\mathrm{cm}}$ at 28 days, are clearly in agreement with this explanation.

Replacement ratios higher than $20 \%$ highly reduced the density and $f_{\mathrm{cm}}$ at all ages, resulting from lower specific gravity of WGP than cement and weak pozzolanic properties of WGP. Ramos et al. [3] reported similar results.

As seen in Figure 10, the downward trend of $f_{\mathrm{cm}}$ in the series without SP (series $\mathrm{W}$ ) is much greater than in the two other series and, in the series containing $4 \mathrm{~kg} / \mathrm{m}^{3}$ ( $1 \%$ of binder weight) SP (series $\mathrm{PF}$ ), the increase in the substitution ratio led to lower drop in $f_{\mathrm{cm}}$ and a better performance. The reason is that this SP content marks the start of the dispersion mechanism of the SP (in this study). The increase in substitution ratio led to an increase of binder volume and subsequently the $\mathrm{SP}^{\prime}$ detachment threshold is not reached and a better performance at high substitution ratios of this series was obtained.

Figure 11 shows the correlation between the binder/aggregates volumetric ratio and $f_{\mathrm{cm}}$ at 28 days. In the series with SP, the volumetric ratio decreased and the $f_{\mathrm{cm}}$ increased, closer to the values of series W. It can be stated that the use of SP in a mix with less cement leads to better results than in a mix with more cement and no SP. Thus using less cement and SP favours the objectives of sustainable development. 


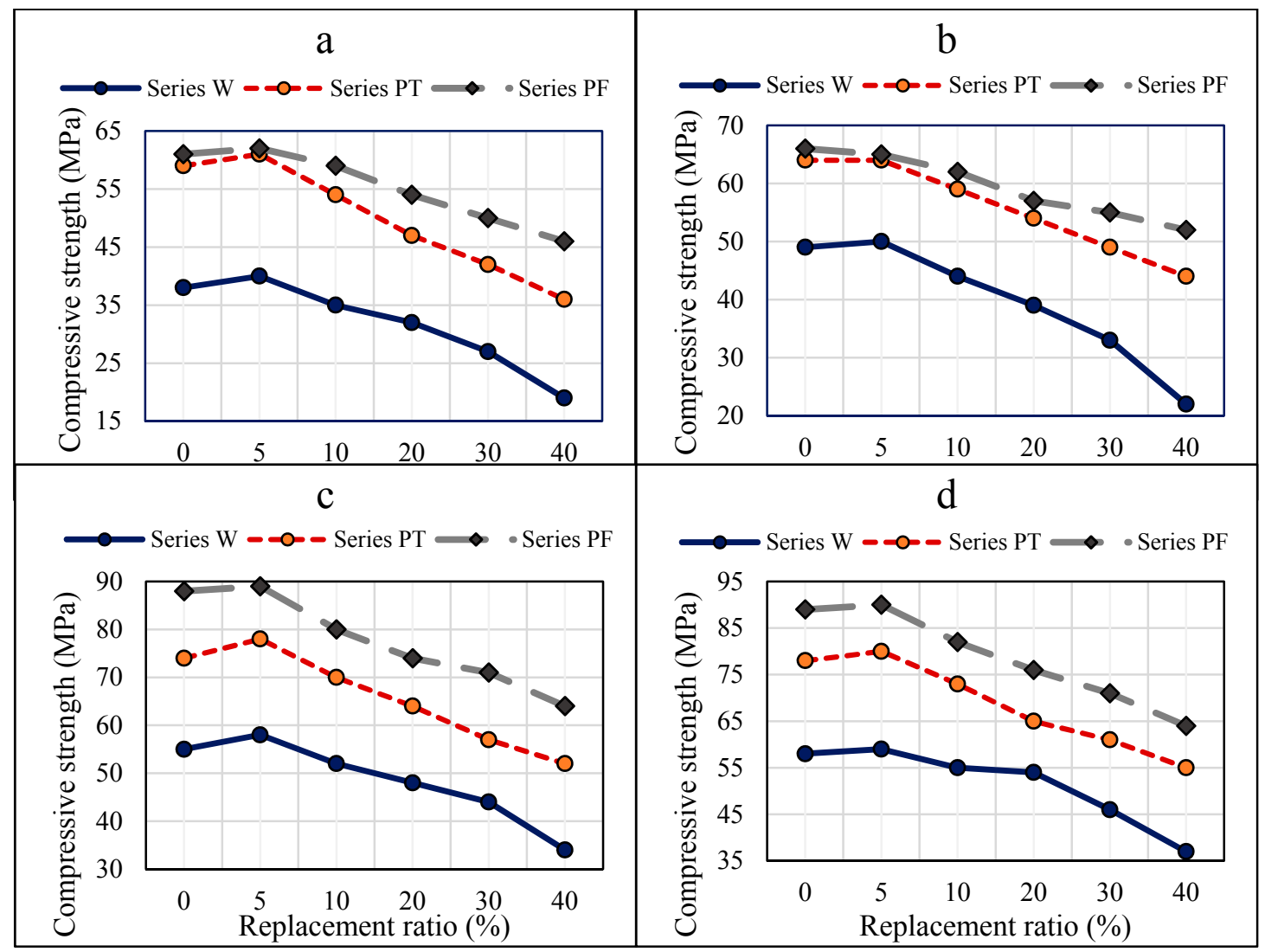

Figure 9. $f_{\mathrm{cm}}$ of concrete mixes at: (a) 7 days; (b) 28 days; (c) 90 days; (d) 180 days.

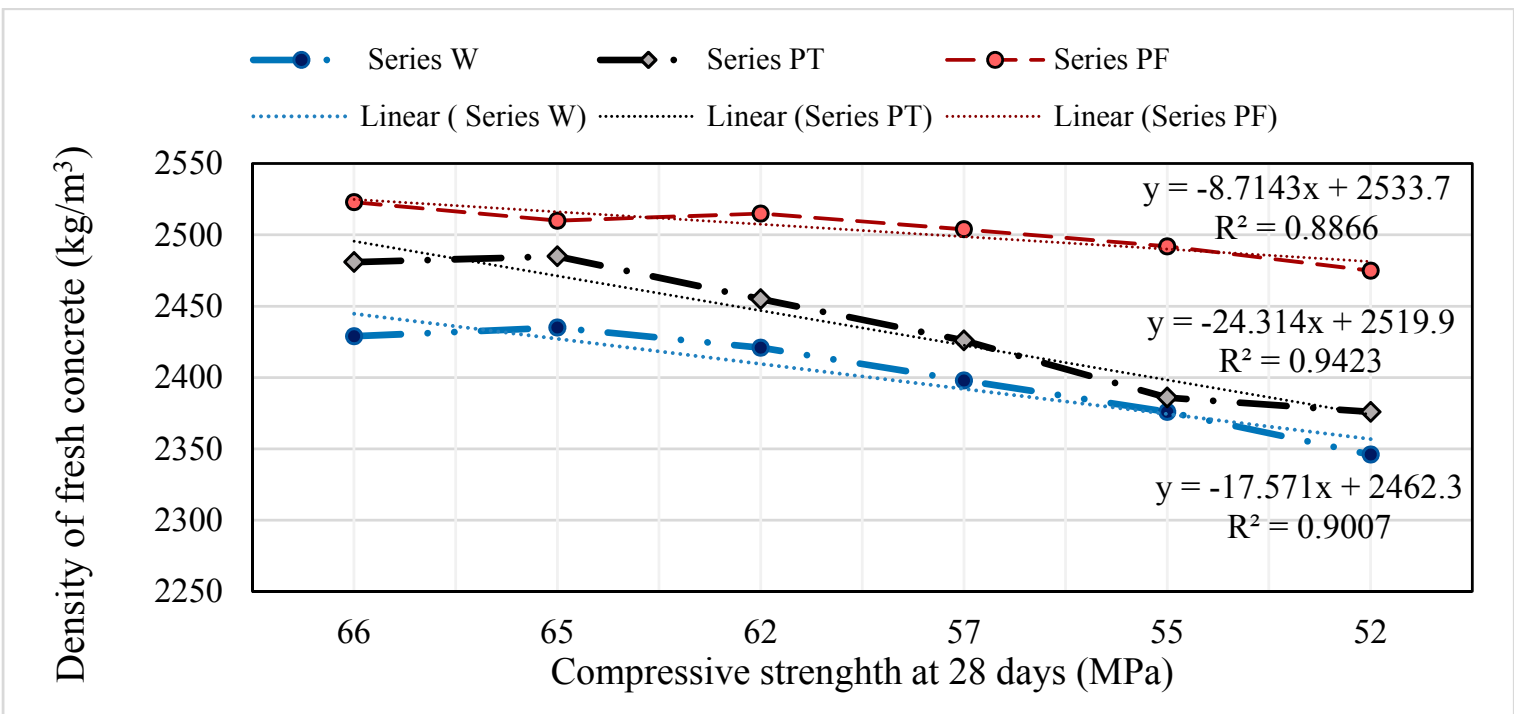

Figure 10. Density of fresh concrete versus $f_{\mathrm{cm}}$ at 28 days. 


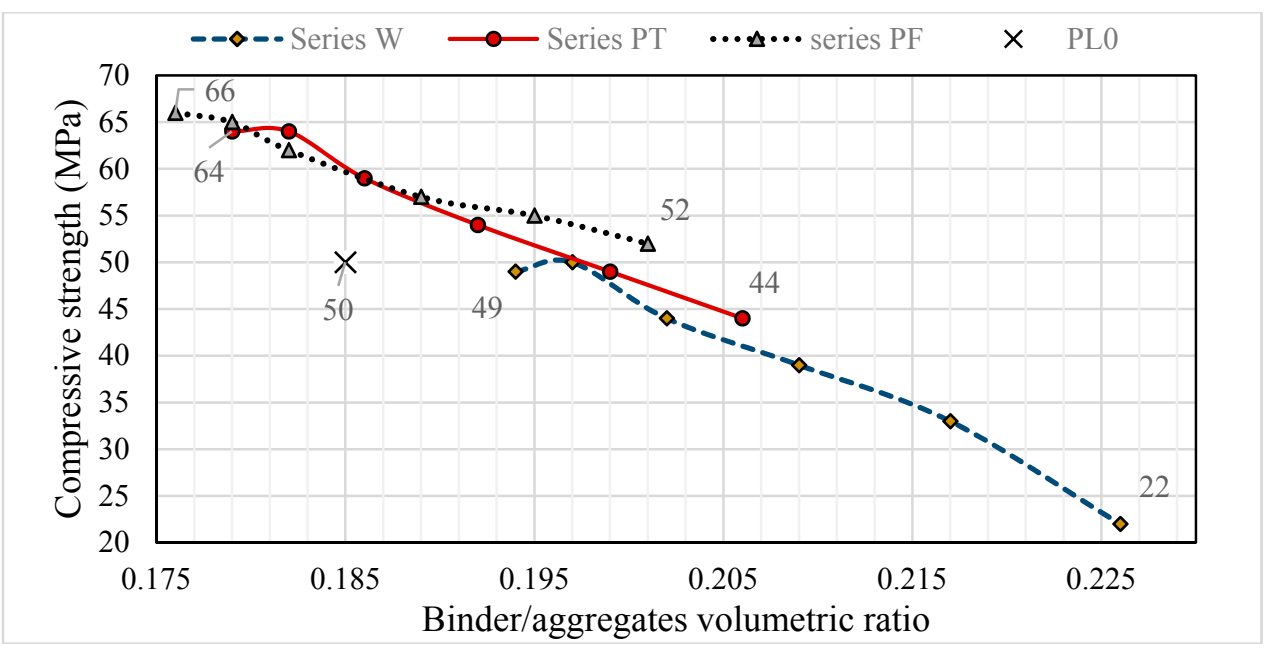

Figure 11. $f_{\mathrm{cm}}$ versus binder/aggregates volumetric ratio.

\subsection{Splitting Tensile Strength}

The $f_{\mathrm{ctm}}$ was determined on cylindrical specimens and the results at different ages (Figure 12). For 5\% replacement ratio, the strength slightly increased but it decreased for higher ratios. The use of a SP had a significant effect on the $f_{\mathrm{ctm}}$ of all mixes.
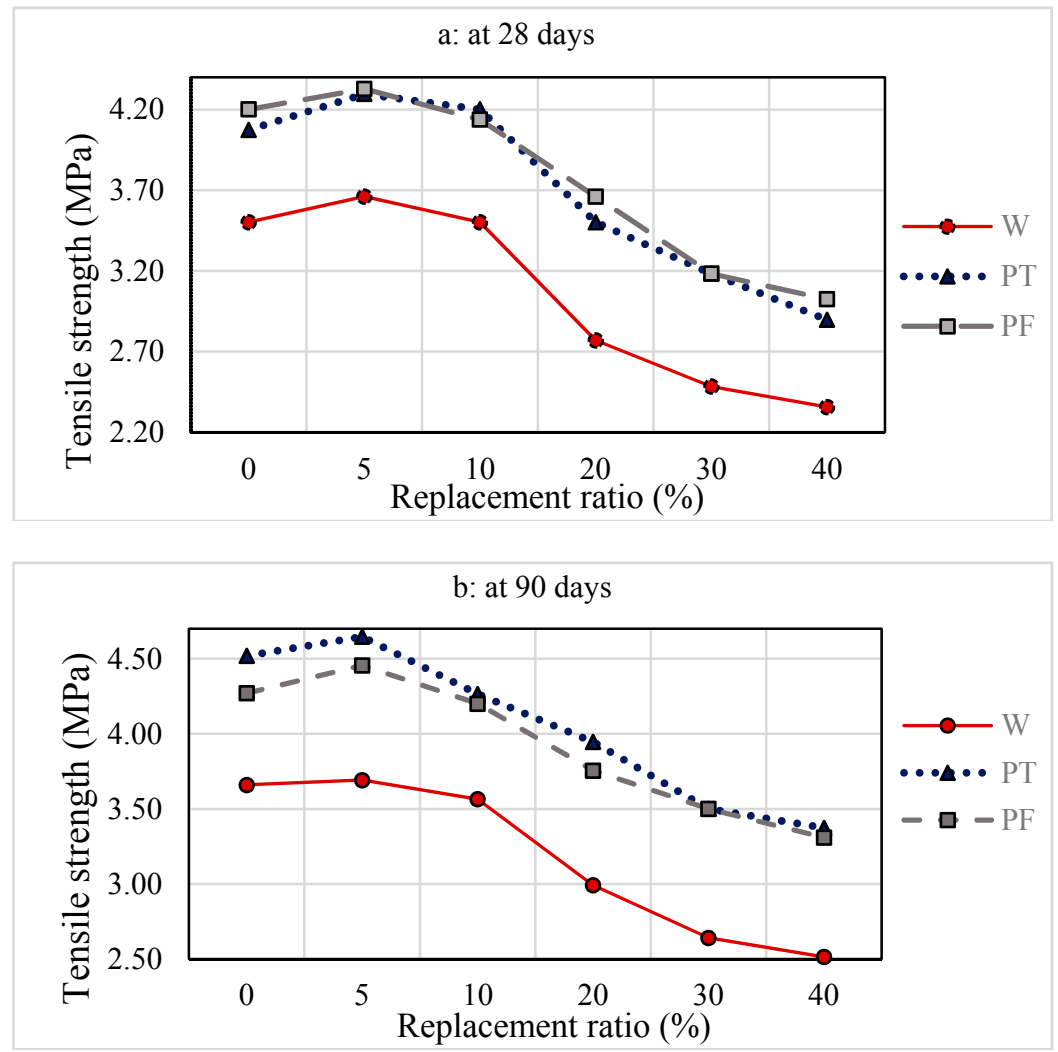

Figure 12. $f_{\mathrm{ctm}}$ at various replacement ratios.

At all testing ages, the results of this study agreed with those of Elmoaty [9] and Vijayalakshmi et al. [45]. It was reported in both of these experiments that the influence of WGP is insignificant on the $f_{\mathrm{ctm}}$ of concrete when it incorporated up to $10 \%$.

Figure 13 shows the $f_{\mathrm{ctm}}$ of mixes relative to the traditional concrete (W0). The greatest increase $(23.71 \%)$ occurred in concrete mix PF5 and the greatest decrease $(32.57 \%)$ in concrete mix W40. In series 
$\mathrm{W}$, for replacement ratios higher than $10 \%$, the $f_{\mathrm{ctm}}$ decreased, while in the other two series increases in $f_{\mathrm{ctm}}$ were observed up to $20 \%$ replacement ratio. This shows that SP have the ability to offset the disadvantages resulting from using WGP in concrete production.

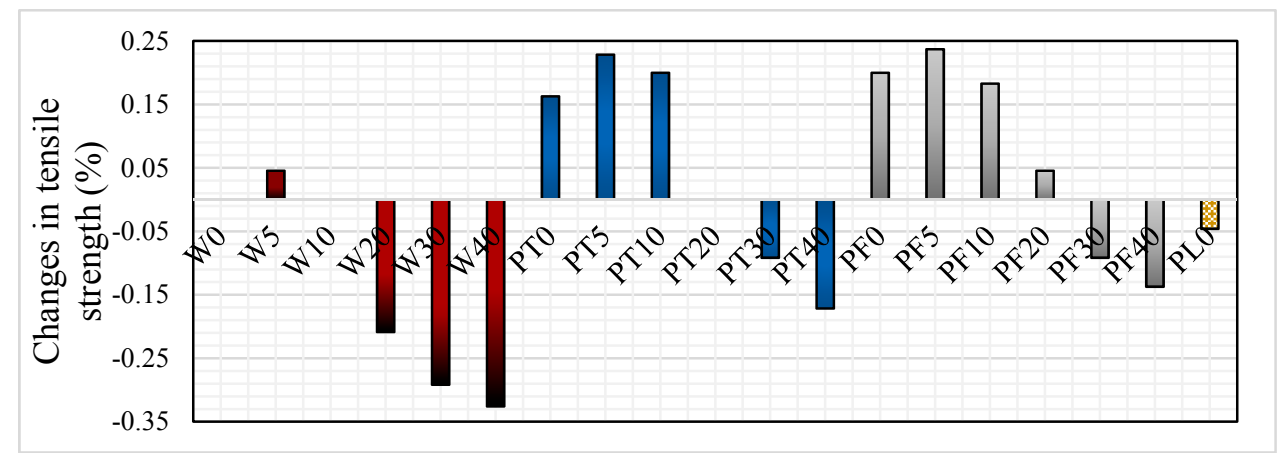

Figure 13. Relative $f_{\mathrm{ctm}}$ of the concrete mixes at 28 days.

\subsection{Electrical Resistivity (ER)}

Changes in electrical properties of concrete are closely related with its evaporable water content, which varies with water/cement ratio, degree of saturation and hydration. The ER depends on the size of the specimen, while the resistivity is an essentially material-related property, so the latter is more frequently used to characterize concrete in electrical methods [27].

The ER of the mixes was obtained after 56 and 180 days of water curing and the values are shown in Figures 14 and 15, respectively.

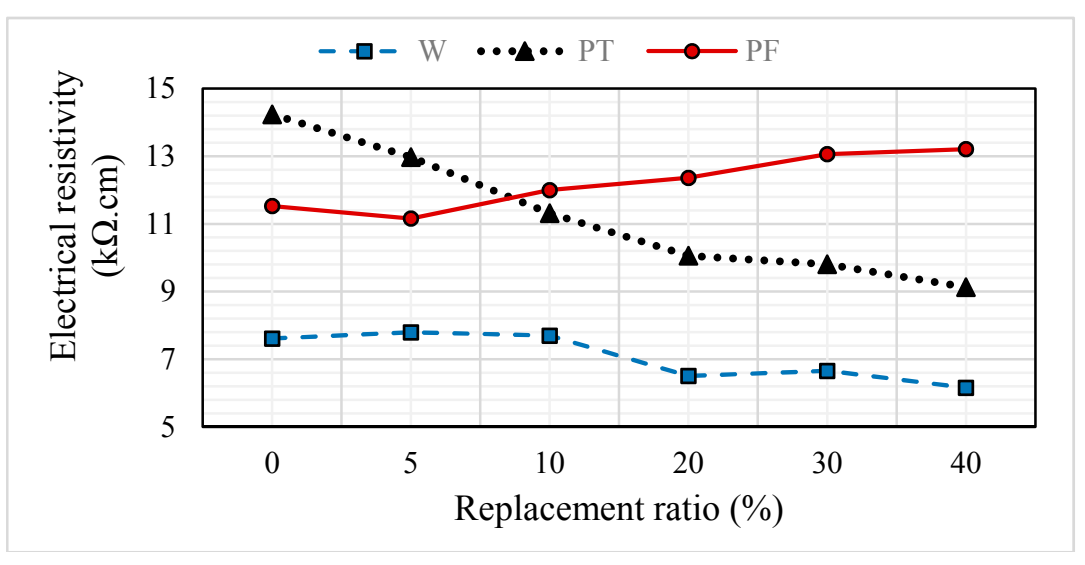

Figure 14. ER at 56 days.

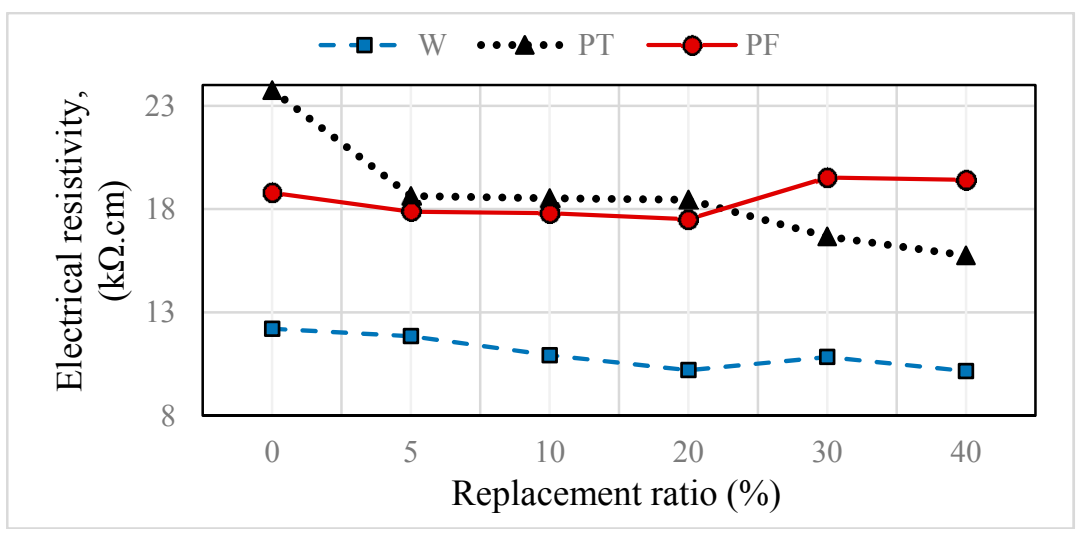

Figure 15. ER at 180 days. 
The ER of concrete is linearly proportional to its pores structure. The resistivity of the mixes of series $\mathrm{W}$ up to $10 \%$ replacement ratio was higher than that of the reference mix. Similarly to [45], the ER of concrete tends to decrease when the replacement ratio increases. In the other two series, the process is significantly different. In series PT, increasing the replacement ratio led to a decrease in ER. Also in this series, the ER is remarkably higher than that of their counterparts in series W due to lower water/binder ratio and the dispersion of cement particles caused by the SP.

The ER of the mix with $40 \%$ WGP and $3 \mathrm{~kg} / \mathrm{m}^{3}$ ( $0.7 \%$ of binder weight) SP is $20 \%$ more than that of the reference concrete. Subsequently, using SP and WGP simultaneously not only eliminates the disadvantages of using waste as cement substitute but also improves the electrical properties of concrete mixes along with being eco-friendly.

The ER of the PF mixes and a few WGP replacement ratios is lower than that of their counterparts in series PT due to reaching the detachment threshold resulting from using too much SP. But a subsequent increase in replacement ratio led to an improvement in the results. The results of series PF showed an upward trend. Finally, the simultaneous effect of reduced water/binder ratio and WGP incorporation can lead to good ER values.

Figure 15 provides the results of ER at 180 days. The trends at 56 days did not change due to the poor pozzolanic activity of WGP but the ER is significantly higher at 180 days than at 56 days.

The percentile changes of all mixes compared to the reference concrete at 56 and 180 days are shown in Figure 16. Mix PT0 experienced the greatest increase in ER.

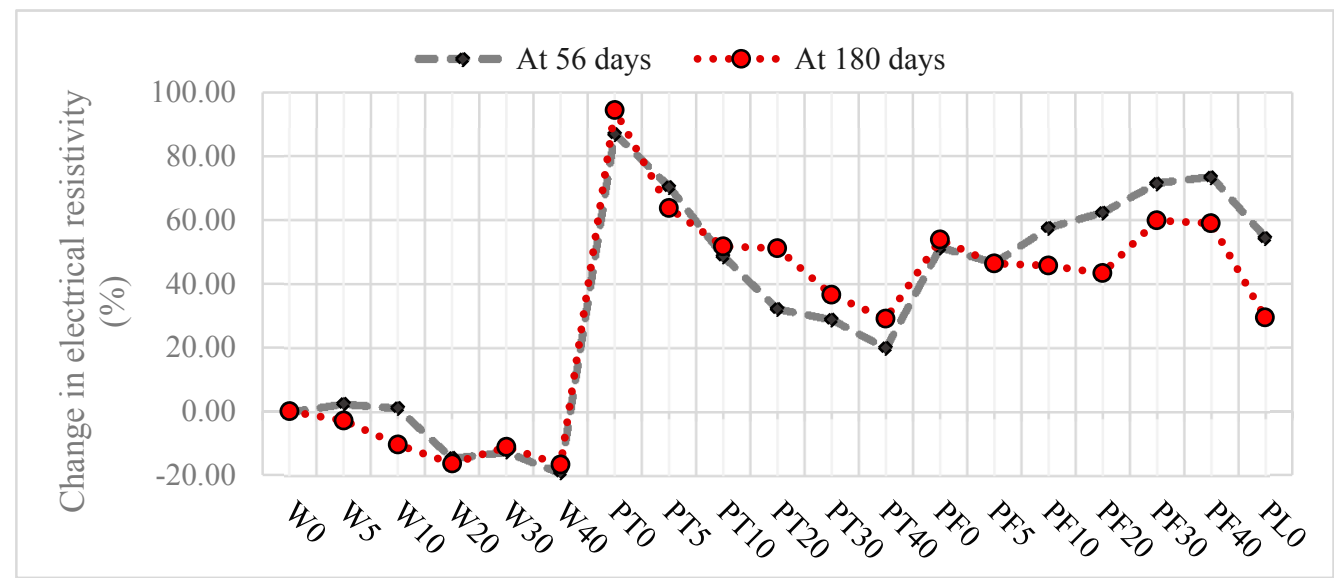

Figure 16. Change in ER of all mixes relative to the reference concrete (W0).

On the other hand, Figure 16 shows that mixes with SP and WGP have much greater ER than their counterparts in series W as well as the reference mix. Thus, it is clear that the use of SP can offset the disadvantages of WGP incorporation and enhance concrete's electrical properties.

\subsection{Resistance of Concrete to Sulphate Attack (SA)}

Figure 17 shows the $f_{\mathrm{cm}}$ of the mixes after exposed to sulphate attack. From series $\mathrm{W}$ and PT, mixes with $20 \%$ and 10\% WGP had the best performance, respectively. But in series PF, mixes containing $20 \%, 30 \%$ and $40 \%$ WGP had the best performance.

According to [8] cement particles reactions take place around the waste particles. In other words, waste particles may act as nucleation sites for the cement reactions, which results in the formation of dense microstructure resulting in the enhancement of the resistance to SA. In addition, because it is non-active, stone waste has a filler effect by filling up the voids between the sand grains. With proper grading, the higher packing results in an improvement of durability by the formation of a dense microstructure. 


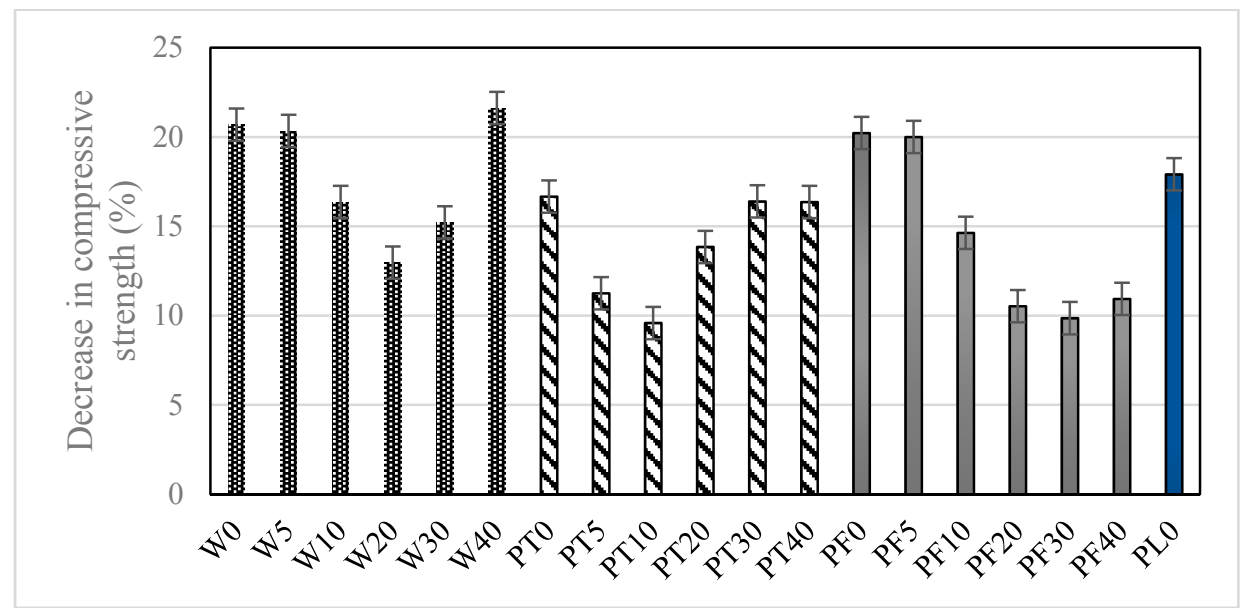

Figure 17. The $f_{\mathrm{cm}}$ decrement due to 180 days SA.

According to these results, it can be said that using SP leads to more resistance to SA, but WGP has much greater effect on this property.

\subsection{Environmental, Economic and Mechanical Indexes}

The three environmental, economic and mechanical indexes for the mixes are shown in Figure 18.

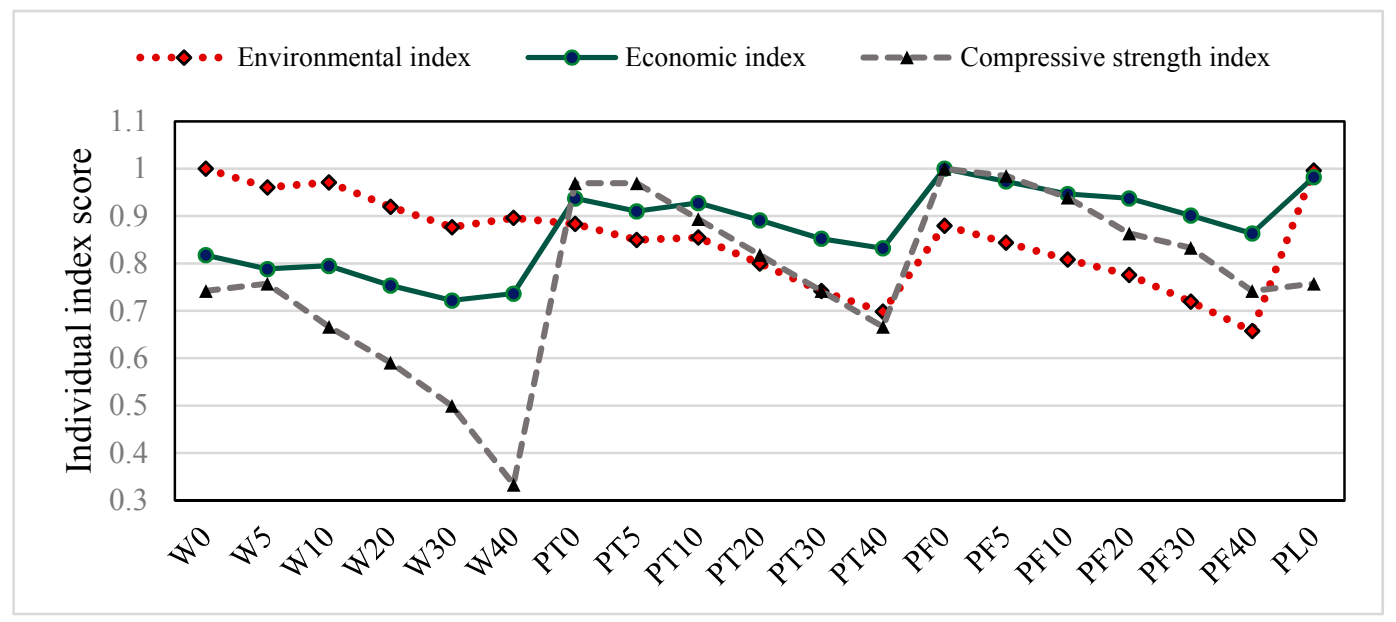

Figure 18. Environmental, economic and mechanical indexes for all mixes.

In series $\mathrm{W}$, the EI is remarkably higher than the other two indexes. But using SP led to lower differences between these values to the extent that the EI became lower than the other two in series PT and PF, meaning that using SP is appropriate from the environmental point of view. In all series, an increase in substitution ratio led to a downward trend of the EI, i.e., towards sustainable development. An increase in SP content and replacement ratio led to an increase and a decrease of the economic index, respectively. Although series $\mathrm{W}$ is the most cost effective one, its mixes are not as environmentally-friendly as the mixes of the two other series, and the mechanical performance is not as high. In series PT, the economic index increases, while the environmental one decreases, and the mechanical performance is by far higher than that of series produced without SP. The upward trend for the economic index continues in series PF and makes the mixes of the series the costlier ones; however, these mixes have the best mechanical performances among all mixes.

Consolidated index values for each concrete mix are provided in Figure 19, according to Equation (11). 


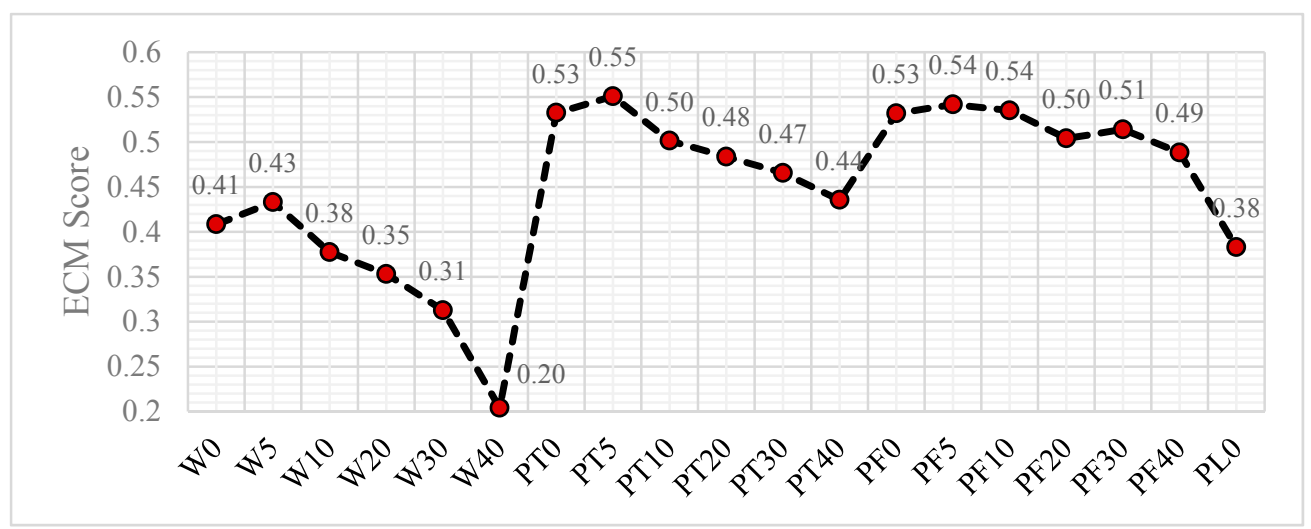

Figure 19. ECM index scores for all concrete mixes.

If the three environmental, economic and mechanical parameters are considered simultaneously, mixes PT5 (0.55), PF5 (0.54) and PF10 (0.54) have the best performance and mix W40 (0.20) has the worst one. In general, concrete mixes containing SP have better performance than the mixes without it. It is clear that using SP significantly increases the multi-criteria performance of concrete; on the other hand, although using WGP helps to decrease the effects of concrete production on the environmental side, it reduces the mechanical performance at high replacement rates, and consequently the multi-criteria performance. Nevertheless, using both WGP and SP in concrete production can results in acceptable ECM scores.

\section{Conclusions}

The experimental program and performance evaluation from different points of view enabled drawing several conclusions related to the use of SP in concrete made with WGP as cement replacement:

- The workability of concrete is affected by WGP incorporation and greater ratios lead to increasingly greater changes. But using SP efficiently decreases the negative effects of waste on workability;

- $5 \%$ WGP content increases the density of concrete, but greater substitution ratios decreases density. The effect of using SP on density is stronger than that of WGP incorporation, but using SP does not change the downward trend of density for replacement ratios over $10 \%$;

- When using SP with less cement content, the results are even much better. Accordingly, using admixtures can be said to be a step towards sustainable development;

- The ER of mix PF40 is $91 \%$ and 59\% more than that of mixes W40 and W0, respectively. Therefore, using SP can be vital to obtain good electrical properties;

- The effect of WGP incorporation on the resistance to SA is much stronger than that of SP. However, using the two materials together provides the best results;

- Using waste in series $\mathrm{W}$ has led to a 0.21 decrease of the ECM index of the mix with $40 \%$ replacement in comparison with the mix produced without WGP, while this decrease is about 0.09 and 0.04 for series PT and PF, respectively. The ECM index of mixes PT0 and PF0 increased by 0.12 compared to mix W0. An increase in the replacement ratio did not significantly change the ECM score in series PT and PF, which proves the importance of using SP.

Author Contributions: E.A.S. and A.K. designed and performed the experiments; E.A.S., M.G. and A.K. analyzed the data and produced the graphs; J.B., M.G. and E.A.S. wrote the manuscript; J.B. and M.G. edited the manuscript.

Funding: This research received no external funding.

Conflicts of Interest: The authors declare no conflicts of interest. 


\section{Abbreviations}

$\begin{array}{ll}\text { ECM } & \text { multi-criteria evaluation index of concrete mixes } \\ \text { EI } & \text { environmental index } \\ \text { ER } & \text { electrical resistivity } \\ \text { GWP } & \text { global warming potential } \\ \text { SA } & \text { sulphate attack } \\ \text { SP } & \text { superplasticizer } \\ \text { SPL } & \text { Lignosulphonate-based superplasticizer } \\ \text { SPP } & \text { polycarboxylate-based superplasticizer } \\ \text { W/c } & \text { water to cement ratio } \\ \text { WGP } & \text { waste granite powder } \\ \text { WU } & \text { water used in concrete production }\end{array}$

\section{References}

1. Kuntz, L.M. The "Greening" of the Concrete Industry: Factors Contributing to Sustainable Concrete. Master's Thesis, Massachusetts Institute of Technology, Cambridge, MA, USA, 2006.

2. Mendoza, J.; Feced, M.; Feijoo, G.; Josa, A.; Gabarrell, X.; Rieradevall, J. Life cycle inventory analysis of granite production from cradle to gate. Int. J. Life Cycle Assess. 2014, 19, 153-165. [CrossRef]

3. Ramos, T.; Matos, A.; Schmidt, B.; Rio, J.; Sousa-Coutinho, J. Granitic quarry sludge waste in mortar: Effect on strength and durability. Constr. Build. Mater. 2013, 47, 1001-1009. [CrossRef]

4. Kala, T. Effect of granite powder on strength properties of concrete. Int. J. Eng. Sci. 2013, 2, 36-50.

5. Lakhani, R.; Kumar, R.; Tomar, P. Utilization of stone waste in the development of value added products: A state of the art review. J. Eng. Sci. Technol. Rev. 2014, 7, 180-187.

6. Ali, N.; Jaffar, A.; Anwer, M.; Alwi, S.; Anjum, M.; Ali, N.; Raja, M.; Hussain, A.; Ming, X. The greenhouse gas emissions produced by cement production and its impact on environment: A review of global cement Processing. Int. J. Res. 2015, 2, 488-500.

7. ASTM C618. Standard Specification for Coal Fly Ash and Raw or Calcined Natural Pozzolan for Use in Concrete; ASTM: West Conshohocken, PA, USA, 2012.

8. Bacarji, E.; Toledo Filho, R.D.; Koenders, E.A.B.; Figueiredo, E.P.; Lopes, J.L.M.P. Sustainability perspective of marble and granite residues as concrete fillers. Constr. Build. Mater. 2013, 45, 1-10. [CrossRef]

9. Elmoaty, A.E.M.A. Mechanical properties and corrosion resistance of concrete modified with granite dust. Constr. Build. Mater. 2013, 47, 743-752. [CrossRef]

10. Mármol, I.; Ballester, P.; Cerro, S.; Monrós, G.; Morales, J.; Sánchez, L. Use of granite sludge wastes for the production of coloured cement-based mortars. Cem. Concr. Compos. 2010, 32, 617-622. [CrossRef]

11. Medina, G.; Sáez del Bosque, I.F.; Frías, M.; Sánchez de Rojas, M.I.; Medina, C. Granite quarry waste as a future eco-efficient supplementary cementitious material (SCM): Scientific and technical considerations. J. Clean. Prod. 2017, 148, 467-476. [CrossRef]

12. Mashaly, A.O.; Shalaby, B.N.; Rashwan, M.A. Performance of mortar and concrete incorporating granite sludge as cement replacement. Constr. Build. Mater. 2018, 169, 800-818. [CrossRef]

13. Medina, G.; Sáez del Bosque, I.F.; Frías, M.; Sánchez de Rojas, M.I.; Medina, C. Durability of new recycled granite quarry dust-bearing cements. Constr. Build. Mater. 2018, 187, 414-425. [CrossRef]

14. Dos Santos Vazzoler, J.; Vieira, G.L.; Teles, C.R.; Degen, M.K.; Teixeira, R.A. Investigation of the potential use of waste from ornamental stone processing after heat treatment for the production of cement-based paste. Constr. Build. Mater. 2018, 177, 314-321. [CrossRef]

15. Pereira, P.; Evangelista, L.; de Brito, J. The effect of superplasticizers on the mechanical performance of concrete made with fine recycled concrete aggregates. Cem. Concr. Compos. 2012, 34, 1044-1052. [CrossRef]

16. Pereira, P.; Evangelista, L.; de Brito, J. The effect of superplasticisers on the workability and compressive strength of concrete made with fine recycled concrete aggregates. Constr. Build. Mater. 2012, 28, 722-729. [CrossRef]

17. Matias, D.; de Brito, J.; Rosa, A.; Pedro, D. Mechanical properties of concrete produced with recycled coarse aggregates-influence of the use of superplasticizers. Constr. Build. Mater. 2013, 44, 101-109. [CrossRef] 
18. Al-Tayeb, M.; Hamouda, H. Effect of superplasticizer on workability of concrete containing crumb rubber. Civ. Environ. Res. 2015, 7, 35-43.

19. Bravo, M.; de Brito, J.; Evangelista, L.; Pacheco, J. Durability and shrinkage of concrete with CDW as recycled aggregates: Benefits from superplasticizer's incorporation and influence of CDW composition. Constr. Build. Mater. 2018, 168, 818-830. [CrossRef]

20. ASTM C136. Standard Test Method for Sieve Analysis of Fine and Coarse Aggregates; American Society for Testing and Materials (ASTM): West Conshohocken, PA, USA, 2014.

21. ASTM C1602. Standard Specification for Mixing Water Used in the Production of Hydraulic Cement Concrete; ASTM: West Conshohocken, PA, USA, 2012.

22. ACI 211.1. Standard Practice for Selecting Proportions for Normal, Heavyweight and Mass Concrete; American Concrete Institute: Farmington Hills, MI, USA, 1991.

23. ASTM C143. Standard Test Method for Slump of Hydraulic-Cement Concrete; ASTM: West Conshohocken, PA, USA, 2008.

24. ASTM C138. Standard Test Method for Density (Unit Weight), Yield, and Air Content (Gravimetric) of Concrete; ASTM: West Conshohocken, PA, USA, 2001.

25. BS EN 12390-3. Testing Hardened Concrete: Compressive Strength of Test Specimens; British Standards Institution: Gunnersbury, UK, 2009.

26. ASTM C496. Standard Test Method for Splitting Tensile Strength of Cylindrical Concrete Specimens; ASTM: West Conshohocken, PA, USA, 2004.

27. Zongjin, L. Advanced Concrete Technology; John Wiley and Sons, Inc.: Hoboken, NJ, USA, 2011.

28. Glavind, M.; Damtoft, J.; Röttig, S. Cleaner technology solutions in the life cycle of concrete products. In Proceedings of the Three-Day International Symposium on Sustainable Development and Concrete Technology, San Fransisco, CA, USA, 16-19 September 2001.

29. Lippiatt, B. BEESRG 2.0: Building for Environmental and Economic Sustainability-Technical Manual and User Guide; National Institute of Standards and Technology: Gaithersburg, MD, USA, 2000.

30. Björklund, T.; Tillman, A. LCA of Building Frame Structures: Environmental Impact Over the Life Cycle of Wooden and Concrete Frames. Technical Environmental Planning Report 2; Chalmers University of Technology: Gothenburg, Sweden, 1997.

31. Josa, A.; Aguado, A.; Heino, A.; Byars, E.; Cardim, A. Comparative analysis of available life cycle inventories of cement in the EU. Cem. Concr. Res. 2004, 34, 1313-1320. [CrossRef]

32. Marceau, M.; Nisbet, M.A.; Van-Geem, M. Life Cycle Inventory of Portland Cement Manufacture; Portland Cement Association Skokie: Skokie, IL, USA, 2006.

33. Sjunnesson, J. Life Cycle Assessment of Concrete. Master's Thesis, Lund University, Lund, Sweden, 2005.

34. CPM LCI Database. Available online: http://www.cpmdatabase.cpm.chalmers.se (accessed on 6 September 2016).

35. Chiaia, B.; Fantilli, A.; Guerini, A.; Volpatti, G.; Zampini, D. Eco-mechanical index for structural concrete. Constr. Build. Mater. 2014, 67, 386-392. [CrossRef]

36. Marinković, S.; Radonjanin, V.; Malešev, M.; Ignjatović, I. Comparative environmental assessment of natural and recycled aggregate concrete. Waste Manag. 2010, 30, 2255-2264. [CrossRef] [PubMed]

37. Rouwette, R. LCA of Geopolymer Concrete (E-Crete); Final Report; Aurora Construction Materials: Epping, Australia, 2012.

38. European Federation of Concrete (EFCA). Environmental Product Declaration, Concrete Admixtures-Plasticisers and Superplasticisers. 2015. Available online: http:/ / www.efca.info (accessed on 6 September 2016).

39. Huang, Y. Life Cycle Assessment of Use of Recycled Materials in Asphalt Pavements. Ph.D. Thesis, Newcastle University, Newcastle upon Tyne, UK, 2007.

40. Flower, D.; Sanjayan, J. Green house gas emissions due to concrete manufacture. Int. J. Life Cycle Assess. 2007, 12, 282-288. [CrossRef]

41. ACI 318. Building Code Requirements for Structural Concrete (ACI 318-08) and Commentary (ACI 318R-08); American Concrete Institute: Farmington Hills, MI, USA, 2008.

42. Valipour, M.; Yekkalar, M.; Shekarchi, M.; Panahi, S. Environmental assessment of green concrete containing natural zeolite on the global warming index in marine environments. J. Clean. Prod. 2014, 65, 418-423. [CrossRef] 
43. Lippiatt, B. BEESRG 3.0: Building for Environmental and Economic Sustainability-Technical Manual and User Guide; National Institute of Standards and Technology: Gaithersburg, MD, USA, 2002.

44. Abukersh, S.; Fairfield, C. Recycled aggregate concrete produced with red granite dust as a partial cement replacement. Constr. Build. Mater. 2011, 25, 4088-4094. [CrossRef]

45. Vijayalakshmi, M.; Sekar, A.; Ganesh prabhu, G. Strength and durability properties of concrete made with granite industry waste. Constr. Build. Mater. 2013, 46, 1-7. [CrossRef] 